\title{
ARD
}

\section{Inhibition of radiographic progression with combination etanercept and methotrexate in patients with moderately active rheumatoid arthritis previously treated with monotherapy}

D van der Heijde, G Burmester, J Melo-Gomes, et al.

Ann Rheum Dis 2009 68: 1113-1118 originally published online August 21, 2008

doi: 10.1136/ard.2008.094375

Updated information and services can be found at:

http://ard.bmj.com/content/68/7/1113.full.html

Topic collections Articles on similar topics can be found in the following collections

Immunology (including allergy) (44279 articles)

Connective tissue disease (7374 articles)

Degenerative joint disease (9543 articles)

Musculoskeletal syndromes (16980 articles)

Rheumatoid arthritis (3573 articles)

\section{Notes}

To order reprints of this article go to:

http://ard.bmj.com/cgi/reprintform

To subscribe to Annals of the Rheumatic Diseases go to: 


\title{
Inhibition of radiographic progression with combination etanercept and methotrexate in patients with moderately active rheumatoid arthritis previously treated with monotherapy
}

\author{
D van der Heijde, ${ }^{1}$ G Burmester, ${ }^{2} \mathrm{~J}$ Melo-Gomes, ${ }^{3}$ C Codreanu, ${ }^{4}$ E Martin Mola, ${ }^{5}$ \\ R Pedersen, ${ }^{6}$ D Robertson, ${ }^{6}$ D Chang, ${ }_{1}^{6}$ A Koenig, ${ }^{6}$ B Freundlich for the Etanercept \\ Study Investigators ${ }^{6}$
}

\begin{abstract}
${ }^{1}$ Rheumatology, Leiden University Medical Center, Leiden, The Netherlands; ${ }^{2}$ Charité Hospital, Humboldt University, Berlin, Germany; ${ }^{3}$ SERVIMED, Lisbon, Portugal; ${ }^{4}$ Centrul de Boli Reumatismale, Bucuresti, Romania; ${ }^{5}$ Hospital La Paz, Madrid, Spain; ${ }^{6}$ Wyeth Research, Collegeville,

Pennsylvania, USA
\end{abstract}

Correspondence to: Professor D van der Heijde, Leiden University Medical Center, P0 Box 9600, 2300RC Leiden, The Netherlands: d.vanderheijde@kpnplanet.n

Accepted 26 July 2008 Published Online First 18 August 2008

\begin{abstract}
Objective: To determine the effect of changing from etanercept or methotrexate monotherapy to etanercept plus methotrexate combination therapy on radiographic progression in rheumatoid arthritis (RA) patients.

Methods: Patients enrolled in this 1-year open-label study previously completed a 3-year blinded study in which they received methotrexate or etanercept monotherapy or the combination of both. All patients received the combination of etanercept $25 \mathrm{mg}$ subcutaneously twice weekly plus oral methotrexate up to $20 \mathrm{mg} /$ week. The primary radiographic endpoint was a change in modified total Sharp score (TSS), as assessed by blinded readers.
\end{abstract}

Results: At baseline, patients previously receiving methotrexate monotherapy (etanercept-added, $n=52$ ) or etanercept monotherapy (methotrexate-added, $\mathrm{n}=68$ ) had moderate disease activity levels (mean disease activity score (DAS) of 2.6 and 2.5, respectively), whereas patients previously receiving combination therapy ( $\mathrm{n}=90$ ) had a low disease activity level (mean DAS of 2.0). The addition of etanercept to methotrexate monotherapy resulted in a significant reduction in radiographic progression $(p<0.05)$. Mean TSS changes in the previous year versus the current year were +1.79 versus +0.25 for the etanercept-added group $(p<0.05)$; +0.51 versus -0.18 for the methotrexate-added group (NS) and +0.42 versus +0.24 for the combination group (NS).

Conclusion: In these RA patients with on average moderate disease activity despite previous methotrexate monotherapy, combination treatment with etanercept and methotrexate inhibited radiographic progression and improved radiographic outcomes. These data, in conjunction with the previously published clinical data, support the use of combination therapy in RA patients with moderate disease activity.

Rheumatoid arthritis (RA) is a chronic, systemic, inflammatory autoimmune disease, which occurs in approximately $1 \%$ of the adult population in western countries, ${ }^{12}$ and is associated with progressive joint destruction, functional disability and increased mortality. ${ }^{3-8}$ Several studies have shown a rapid rate of progression in erosion and cartilage destruction in the early years of the disease that appeared to decrease in later disease. ${ }^{79-13}$ In a 3-year study in patients with early RA, van der Heijde et $a l^{10}$ observed an initial rate of radiographic progression of 14 standard units (SU) in total Sharp score (TSS), out of a maximum of $448 \mathrm{SU}$, in the first year and a progression to $9 \mathrm{SU}$ in the subsequent 2 years during treatment with conventional disease-modifying antirheumatic drugs (DMARD). Moderate loss of functional ability may develop in half of affected individuals within 2 years of RA diagnosis. ${ }^{8}$ Therefore, treatment of RA with effective therapy early in the disease course is recommended, with the goal of long-term remission and prevention or limitation of joint damage and functional loss. ${ }^{14}$

Among the DMARD currently used in RA, methotrexate is often selected first, particularly for patients with more active disease, because randomised, controlled clinical trials have established its efficacy in improving symptoms and function and in slowing the progression of joint erosion. ${ }^{14}$ However, several trials have shown that joint destruction continues even with the use of high-dose methotrexate $e^{15-20}$ as well as sequential DMARD monotherapy or step-up combination DMARD therapy. ${ }^{21}$ In addition, the majority of patients discontinue most conventional DMARD regimens within 2 years, most often because of insufficient efficacy or intolerability. ${ }^{22}$ Biological drugs that selectively block tumour necrosis factor (TNF), a pro-inflammatory cytokine involved in the pathogenesis of RA, ${ }^{23}$ have become an important therapeutic option in RA. Clinical trial data have demonstrated that the use of TNF antagonists, alone or in combination with methotrexate, is effective in improving both clinical and radiographic outcomes in patients with RA. ${ }^{16-2024-28}$ Although these newer antirheumatic medications and regimens are highly effective, there is still more to learn about which patients should be treated with these therapies.

In this study, we provide the radiographic results of a 1-year study in which patients with RA who previously completed 3 years of a blinded therapy with methotrexate or etanercept alone or a combination of both all received treatment with the combination of etanercept and methotrexate for 1 year. The results of the clinical outcomes ${ }^{25}$ demonstrated that patients with partial response to long-term monotherapy and a mean moderate disease activity level can obtain a greater benefit with combination therapy and that patients can 
sustain the benefit or continue to show improvement through 4 years of combination therapy.

\section{PATIENTS AND METHODS}

A detailed description of the study design is provided elsewhere. ${ }^{25}$ In brief, RA patients who completed 3 years of treatment with methotrexate, etanercept, or a combination of both in a double-blind study ${ }^{18} 29{ }^{30}$ were eligible to enroll in the current study. All enrolled patients received both open-label etanercept $25 \mathrm{mg}$ subcutaneously twice weekly and oral methotrexate at individualised doses up to $20 \mathrm{mg} /$ week. Radiographic evaluations were performed at baseline of the current study and at year 1 .

The study protocol and an informed consent form received approval by the independent ethics committee or institutional review board at each institution before study initiation. All participating patients provided written informed consent before enrollment in the study. The study was conducted in accordance with the ethical principles of the Declaration of Helsinki.

\section{Radiographic assessments}

Radiographs of the hands, wrists and forefeet were taken at the baseline visit (post 3-year, double-blinded portion of the study) and at week 52 or the final study visit. In addition, the films from years 2 and 3 of the prior double-blind study were reanalysed, allowing evaluation of changes in radiographic progression before and after the initiation of combination therapy in patients receiving previous monotherapy and with the continuation of combination therapy in those receiving previous combination therapy. The primary radiographic endpoint was the change from baseline in the van der Heijdemodified TSS, ${ }^{31}$ which was calculated from baseline to year 1 or the final study visit for all patients with valid radiographic data. Other radiographic assessments included changes from baseline to year 1 in erosion and joint space narrowing (JSN) scores; differences in annualised rates of change in modified TSS, along with erosion and JSN scores, from the year before the current study (when patients were receiving blinded monotherapy or combination therapy) and the current 1-year study period; and the proportion of patients with radiographic non-progression, defined as modified TSS change of 0.5 or less and as modified TSS change of 0.0 or less. The changes from baseline in modified TSS were presented in cumulative probability plots to allow visualisation of all radiographic data over the 1-year period. Frequency distributions of the observed cumulative proportion, by which scores were ranked from lowest to highest by treatment group and expressed as a cumulative percentage of all scores, were plotted against the actual change in modified TSS.

Radiographs from each patient were acquired according to procedures prepared by Bio-Imaging Technologies (Newtown, Pennsylvania, USA), which also digitised and archived the images. Two independent physicians read the digitised image sets of radiographic films for each patient in random sequence using a computer-assisted masked reading method. The readers remained blinded to the treatment groups of the previous 3-year study and to the order of radiographs throughout the reading process. An image set was composed of images from three time points: the final visits of year 2 of the previous doubleblind study and the baseline visit (same as year 3 of the previous study) and the final visit of the current study. The average score of the two readers was used in the analyses. To validate reader reliability, inter-reader and intra-reader variability intraclass correlations were calculated. Five per cent of images were read twice and scores from the second reading were compared with those from the first reading to determine intrareader correlations. Status scores on all images from all patients read by both readers were used to calculate inter-reader variability.
Figure 1 Patient disposition. ETN, etanercept; MTX, methotrexate.

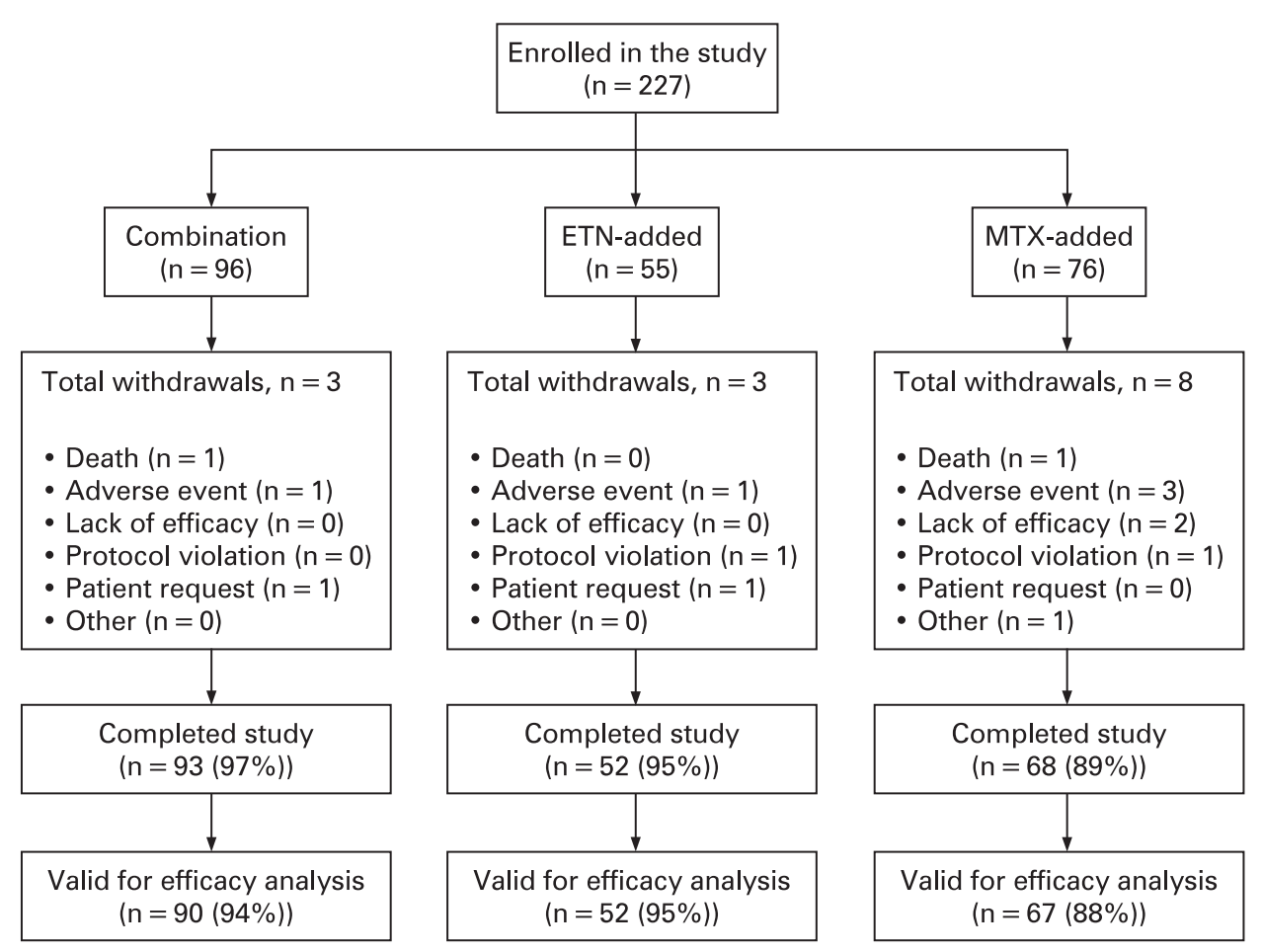




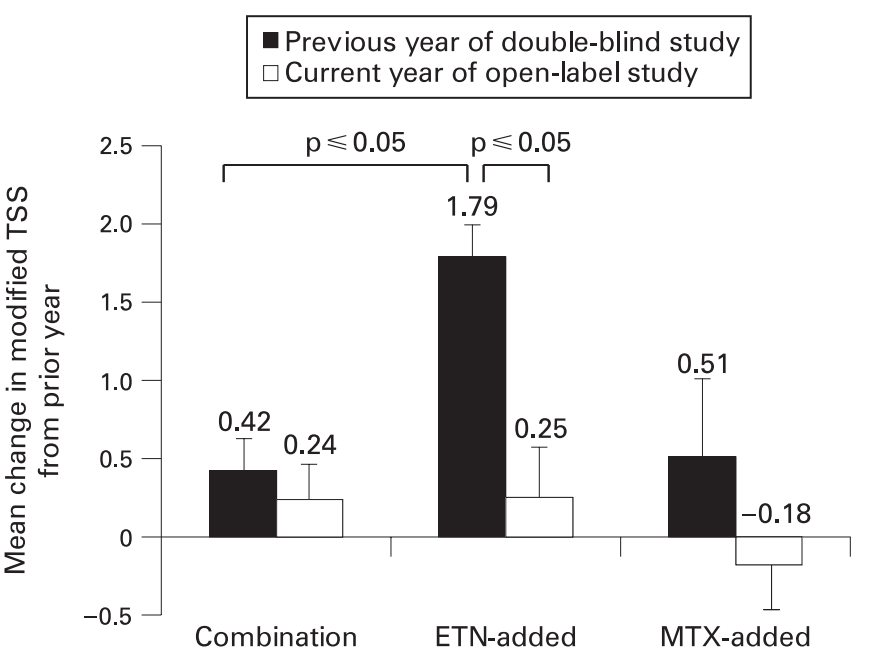

Figure 2 Mean change in modified total Sharp score (TSS) by treatment group from year 2 to year 3 of the previous double-blind study and from baseline to year 1 of the current study. ETN, etanercept; MTX, methotrexate.

\section{Statistical analysis}

The number of patients who completed year 3 of the previous double-blind study $(\mathrm{n}=327)$ determined the sample size in this study, because only these patients were eligible for enrollment in the current open-label extension. Changes from baseline in modified TSS and erosion and JSN scores were analysed in all enrolled patients who received at least one dose of study drug and had readable baseline and on-therapy radiographs for the current 1-year study. For patients who did not complete the study, radiographs were taken at the final study visit and radiographic progression was imputed by linear extrapolation.

Radiographic assessments were analysed using an analysis of covariance (ANCOVA) model based on the ranks of the average scores from the two readers, including factors for baseline modified TSS rank, treatment group and methotrexate use before the original double-blind study initiation as covariates. ANCOVA results were accompanied by $95 \%$ CI. Radiographic non-progression (modified TSS change $\leqslant 0.5$ and modified TSS change $\leqslant 0.0$ ) was analysed using a Mantel-Haenszel approach, with stratification by study centre and prior methotrexate use. Inter-reader and intra-reader correlation coefficients were determined by analysis of variance. ${ }^{32}$

Clinical efficacy and safety analyses were performed using a modified intention-to-treat approach in which all patients who were randomly assigned and received at least one dose of study drug were included. The last-observation-carried-forward method was used to account for missing data when assessing clinical endpoints. All tests and confidence intervals were twosided at an alpha of 0.05 .

\section{RESULTS}

\section{Patients and disposition}

Of 686 patients randomly assigned in the original double-blind study, ${ }^{29} 327$ completed all 3 years of treatment. One hundred of these patients did not participate in the current study because they elected not to continue $(\mathrm{n}=19)$ or their site discontinued participation in the study for non-medical reasons $(\mathrm{n}=81)$, the most common being investigator lack of interest and regulatory document submission delays.
Of the 246 patients eligible to participate in this study, 227 patients $(92.3 \%)$ were enrolled: 96 patients were previously treated with the combination of etanercept and methotrexate (combination); 55 patients with methotrexate monotherapy (etanercept-added); and 76 patients with etanercept monotherapy (methotrexate-added). Seventeen of the 227 enrolled patients $(7.5 \%)$ were excluded from the radiographic intention-to-treat population (six patients in the combination group, three patients in the etanercept-added group and eight patients in the methotrexate-added group) because the required radiographs were not obtained $(\mathrm{n}=10)$ or were unreadable $(\mathrm{n}=7)$. An additional patient, who received etanercept monotherapy in the double-blind study, was excluded from the comparative analyses of radiographic progression between baseline (year 3 of double-blind treatment) and 1 year of openlabel treatment because valid radiographs were not available from the original study. A total of 213 patients (93.8\%) completed the 1-year study (fig 1); 209 patients were included in the radiographic intent-to-treat analysis.

Baseline demographics of the population enrolled in the current study were similar across treatment groups. Details have been published previously. ${ }^{182529}$ At baseline of this study, patients in the combination group had lower disease activity than those in the other two treatment groups. The mean disease activity score (DAS) of 2.0 in the combination group was in the low disease activity range $(\mathrm{DAS}<2.4)$ and significantly lower $(p<0.05)$ than the mean DAS of 2.6 and 2.5 in the etanercept-added and methotrexate-added groups, respectively, which were both in the moderate disease activity range.

\section{Radiographic efficacy}

\section{Changes in modified TSS and erosion and JSN scores}

For all three treatment groups, the change in modified TSS was less during the current study on combination therapy than during the last year in the blinded study. However, only the addition of etanercept to methotrexate monotherapy resulted in a statistically significant reduction in radiographic progression during the year of open-label treatment $(+1.79$ to $+0.25, \mathrm{p}<0.05$; fig 2). During treatment with combination etanercept and methotrexate therapy, all three groups demonstrated a mean radiographic progression of 0.25 or less. The mean changes in erosion scores during the last year of the double-blind study were $+0.19,+0.66$ and +0.21 for the combination, etanerceptadded, and methotrexate-added groups, respectively. One year after combination therapy was administered to all patients in the current study, the erosion scores decreased to $+0.06,+0.27$ and 0.00 , respectively. Similarly for JSN, the scores for the last year were $+0.24,+1.12,+0.30$ for the combination, etanerceptadded, and methotrexate-added groups, respectively, which improved to $+0.18,-0.02,-0.18$ after treatment with combination therapy for 1 year.

Cumulative probabilities of individual changes from baseline in modified TSS during the 1-year period of the study, during which all patients received combination therapy with etanercept and methotrexate, are shown in fig 3 . The majority of patients in all groups showed no progression or negative scores. The etanercept-added group included the highest percentage of patients with progression.

\section{Radiographic non-progression}

The percentage of patients with no progression of joint damage, when defined as modified TSS change of 0.5 or less, increased 


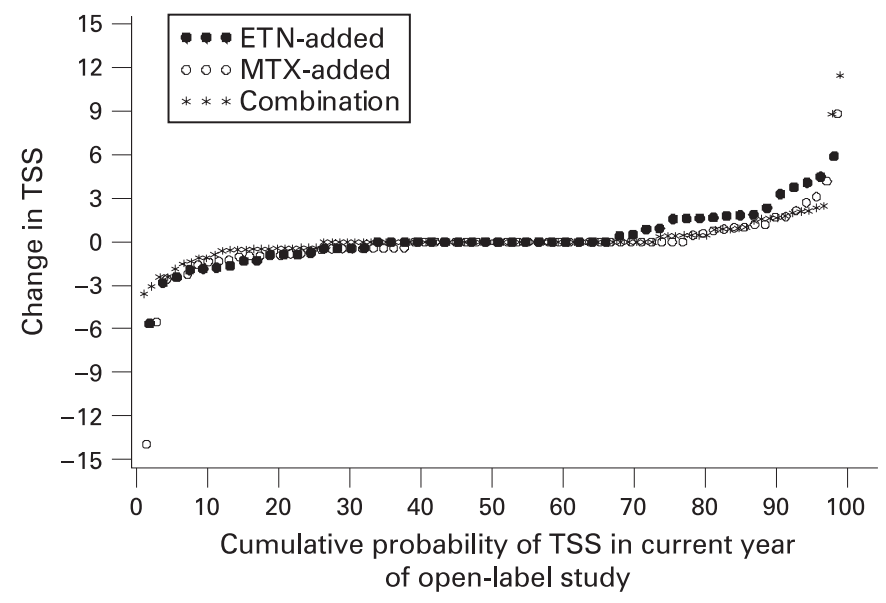

Figure 3 Probability plots of individual changes from baseline in modified total Sharp score (TSS) during the current 1-year study for the combination, etanercept (ETN)-added and methotrexate (MTX)-added groups.

significantly for the etanercept-added group from year 3 to the current study (from $51.9 \%$ to $69.2 \%$, p $<0.05$; fig 4 ); the other groups also demonstrated higher rates of non-progression in the study, but these were not significant. The results were similar when the radiographic non-progression definition was based on a modified TSS change of 0.0 or less. The etanercept-added group improved from $44.2 \%$ to $67.3 \%(p<0.05)$; the methotrexate-added group improved from $62.7 \%$ to $77.9 \%(p=N S)$ and the combination group improved from $68.9 \%$ to $73.3 \%$ $(\mathrm{p}=\mathrm{NS})$.

\section{Inter and intra-reader correlation}

Inter-reader correlation coefficients on erosion, JSN and TSS status scores at year 2 and year 3 ranged from 0.79 to 0.93 ; corresponding intra-reader correlation coefficients on radiological scoring data were 0.94 to 0.98 .

\section{DISCUSSION}

The purpose of the current study was to determine whether previous monotherapy responders with a residual moderate disease activity level on average after long-term methotrexate or etanercept monotherapy would achieve further clinical and radiographic benefit from combination therapy with these agents. As reported elsewhere, ${ }^{25}$ the combination group had low disease activity at the baseline of this study, whereas the etanercept-added and methotrexate-added groups had moderate disease activity. At week 52, all three treatment groups showed low disease activity (DAS $<2.4$ ) on average, with DAS of 1.9, 1.9 and 2.2 reported in the combination, etanercept-added and methotrexate-added groups, respectively $(p<0.05$ within group). Patients in the etanercept-added group achieved the greatest increase in DAS remission rates from the extension study baseline to week $52(23.6 \%$ to $41.8 \%, \mathrm{p}<0.01)$; patients in the combination $(37.6 \%$ to $50.0 \%, \mathrm{p}<0.01)$ and methotrexateadded $(26.7 \%$ to $36.8 \%, p=N S)$ groups also demonstrated improvements. In addition, during the 52-week extension, combination treatment was associated with a favourable safety profile; no new unexpected safety signals or toxicities were observed. No cases of tuberculosis, opportunistic infections, systemic lupus erythematosus, or central demyelinating disorders occurred and serious infections were uncommon. ${ }^{25}$

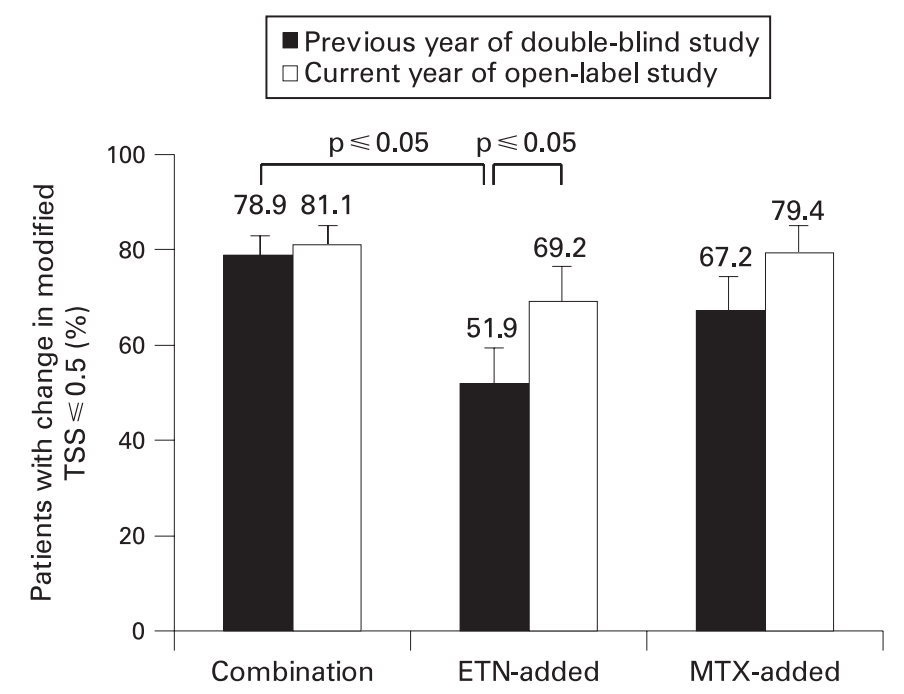

Figure 4 Percentage of patients by treatment group with no radiographic progression, defined as change in modified total Sharp score (TSS) $\leqslant 0.5$, from year 2 to year 3 of the previous double-blind study and from baseline to year 1 of the current study. ETN, etanercept; MTX, methotrexate.

The results reported here indicate that 1 year of combination therapy can also provide additional radiographic improvement for patients with average moderate disease activity after 3 years of monotherapy. Moreover, continuation of combination therapy after 3 years of this regimen sustained or improved the prevention of radiographic progression from year 3 of the double-blind study to the end of the current 1-year study. Previous studies have shown that clinically relevant progression of joint damage can occur in patients with RA achieving persistent clinical remission with conventional DMARD therapy. ${ }^{33}{ }^{34}$ Similarly, in an analysis of the 3-year Trial of Etanercept and Methotrexate with Radiographic and Patient Outcomes (TEMPO) data, mean radiographic progression rates continued to increase, even in patients treated with methotrexate alone who were in clinical remission or who had very low disease activity. ${ }^{35}$ Overall, however, increased radiographic progression was linked to increasing systemic inflammatory activity in those receiving methotrexate monotherapy. In contrast, patients treated with the combination of etanercept and methotrexate demonstrated inhibition of joint destruction independent of inflammatory activity. Moreover, even in patients with the lowest level of inflammation, progression of joint damage with combination therapy was at a significantly lower level than that with methotrexate alone. The radiographic progression that occurs despite good clinical response may support the need for more aggressive therapy than conventional DMARD. A more intensive therapeutic strategy could be considered to extend the standard of care beyond the control of disease activity to include radiographic non-progression and prevention of functional loss. The gain in long-term outcome in terms of function, ability to work and participation should be weighed against the extra costs involved in such a strategy.

The TEMPO study was the first to demonstrate that the combination of etanercept and methotrexate inhibits radiographic progression more than methotrexate or etanercept monotherapy. Although patients receiving etanercept and methotrexate monotherapies showed similar clinical improvement in both the second and third years of the double-blind 
study, those receiving methotrexate monotherapy had greater increases in radiographic damage during these intervals. ${ }^{18}{ }^{30}$ In patients who received the methotrexate-only regimen for 3 years, adding etanercept for 1 year in this study significantly reduced the rate of radiographic progression; patients who had received etanercept monotherapy or combination therapy for 3 years demonstrated some reductions in radiographic progression during this year of combination therapy, although these changes were not significant. Whereas the rate of radiographic non-progression was significantly increased with the addition of etanercept in the methotrexate monotherapy group (69\%), it ultimately did not reach the levels achieved in the groups that previously received either etanercept alone or in combination (79\% and $81 \%$, respectively). The observed difference in frequency of non-progression indicates that earlier use of combination etanercept-methotrexate treatment may provide a meaningful reduction in joint destruction compared with methotrexate alone.

Despite the minimal radiographic progression in all groups with combination therapy, treating patients for 3 years with methotrexate monotherapy before adding etanercept may have already led to some irreversible joint damage. For the methotrexate monotherapy group that added etanercept in this study, the mean radiographic progression was only +0.25 modified TSS units. However, during the last year of methotrexate monotherapy, the mean progression was +1.79 and during the first 2 years of methotrexate monotherapy in TEMPO, the mean progression was $+3.34 .{ }^{30}$ In contrast, the combination group demonstrated a mean progression of +0.24 in this study, compared with +0.42 in the last year and -0.56 in the first 2 years of TEMPO. ${ }^{30}$ The composite mean progression after 3 years of treatment with methotrexate alone was +5.13 , compared with +0.10 after 4 years of combination treatment with etanercept plus methotrexate. Although these data represent mean values for the two groups, it may be worth noting that, in individual patients, progression in modified TSS of more than 5 units with methotrexate monotherapy over 3 years represents a clinically important progression based on international expert panel findings. ${ }^{36}$

These radiographic results augment the previously reported clinical findings, ${ }^{25}$ showing that patients who have improved from a mean of severe to moderate disease activity with methotrexate treatment continue to experience progressive radiographic damage that can be blocked by the addition of etanercept. Combination treatment with etanercept plus methotrexate provided enhanced protection against joint damage in patients with RA who had moderate disease activity despite monotherapy with either agent. Although all three groups showed some improvement, this benefit was particularly pronounced when etanercept was added to methotrexate monotherapy. The radiographic improvements achieved by patients treated with combination therapy for 3 years in the original double-blind study were sustained or improved during the fourth year of open-label treatment. The results of this study support the use of combination therapy with etanercept and methotrexate in patients with moderate disease on methotrexate monotherapy and suggest that earlier combination therapy could be considered in these patients.

Acknowledgements: The authors would like to thank Joanne Estojak and David MacPeek for supporting the conduct and monitoring of the study and Donna McGuire and Joanne Foehl for assistance with the preparation and review of the manuscript.

Funding: This study was supported by Wyeth Pharmaceuticals, Collegeville, Pennsylvania, USA.
Competing interests: DvdH has received consulting fees, research grants, and/or speaking fees from Abbott, Amgen, Aventis, Bristol Myers Squibb, Centocor, Pfizer, Roche, Schering Plough, UCB and Wyeth; GB has received honoraria and fees for lectures, consulting and research grants from Wyeth; JM-G participated as an investigator for this Wyeth-funded study; CC received funding for research and speaker fees from Wyeth; EMM has received fees as a consultant and for organising educational programmes for Abbott, Centocor, Schering-Plough and Bristol Myers Squibb; DC was employed by Wyeth Pharmaceuticals at the time of study conduct; $\mathrm{RP}, \mathrm{DR}, \mathrm{AK}$ and $\mathrm{BF}$ are employed by and have stock options with Wyeth Pharmaceuticals.

Ethics approval: The study protocol and an informed consent form received approval by the independent ethics committee or institutional review board at each institution before study initiation. The study was conducted in accordance with the ethical principles of the Declaration of Helsinki.

\section{Patient consent: Obtained.}

Etanercept study $\mathbf{4 0 0}$ investigators: HD Bolosiu, Cluj-Napoca, Romania; J Brzezicki, Elblag, Poland; G-R Burmester, Berlin, Germany; B Canesi, Milano, Italy; H ChwalinskaSadowska, Warszawa, Poland; C Codreanu, Bucuresti, Romania; M Cutolo, Genova, Italy; J de Melo Gomes, Lisboa, Portugal; A Filipowicz-Sosnowska, Warszawa, Poland; S Freiseleben-Sorensen, Copenhagen, Denmark; P Geusens, Diepenbeek, Belgium; JJ Gómez Reino, Santiago de Compostela, Spain; N Graudal, Herlev, Denmark; G HerreroBeaumont, Madrid, Spain; M Janssen, Arnhem, The Netherlands; H Julkunen, Vantaa, Finland; J Kalden, Erlangen, Germany; J Kekow, Vogelsang, Germany; A Laffón, Madrid, Spain; H Lang, Plauen, Germany; P Lanting, Doetinchem, The Netherlands; R Luosujarvi, Kuopio, Finland; R Luukkainen, Satalinna, Finland; M Malaise, Liege, Belgium; E Martín Mola, Madrid, Spain; Z Mencel, Kalisz, Poland; C Montecucco, Pavia, Italy; K Pavelka, Prague, Czech Republic; A Perniok, Köln, Germany; F Radulescu, Bucuresti, Romania; R Sanmartí, Barcelona, Spain; L Settas, Thessaloniki, Greece; H Stehlikova, Ceska Lipa, Czech Republic; J Szechinski, Wroclaw, Poland; J Szerla, Krakow, Poland; C Tanasescu, Bucuresti, Romania; J Tornero, Guadalajara, Spain; S Transo, Jonkoping, Sweden; T Tuomiranta, Tampere, Finland; S Valtysdottir, Uppsala, Sweden; E Veys, Gent, Belgium; H Van den Brink, Alkmaar, The Netherlands; M Van de Laar, Enschede, The Netherlands; P Vitek, Zlin, Czech Republic; R Zahora, Terezin, Czech Republic.

\section{REFERENCES}

1. Abdel-Nasser AM, Rasker JJ, Valkenburg HA. Epidemiological and clinical aspects relating to the variability of rheumatoid arthritis. Semin Arthritis Rheum 1997;27:123-40.

2. Helmick CG, Felson DT, Lawrence RC, Gabriel S, Hirsch R, Kwoh CK, et al, for the National Arthritis Data Workgroup. Estimates of the prevalence of arthritis and other rheumatic conditions in the United States: part I. Arthritis Rheum 2008;58:15-25.

3. Pincus T, Callahan LF, Sale WG, Brooks AL, Payne LE, Vaughn WK. Severe functional declines, work disability, and increased mortality in seventy-five rheumatoid arthritis patients studied over nine years. Arthritis Rheum 1984;27:864-72.

4. Wolfe F, Mitchell DM, Sibley JT, Fries JF, Bloch DA, Williams CA, et al. The mortality of rheumatoid arthritis. Arthritis Rheum 1994;37:481-94.

5. Corbett M, Dalton S, Young A, Silman A, Shipley M. Factors predicting death, survival and functional outcome in a prospective study of early rheumatoid disease over fifteen years. Br J Rheumatol 1993;32:717-23.

6. Scott DL, Smith C, Kingsley G. Joint damage and disability in rheumatoid arthritis: an updated systematic review. Clin Exp Rheumatol 2003;21(5 Suppl 31):S20-7.

7. Sharp JT, Wolfe F, Mitchell DM, Bloch DA. The progression of erosion and joint space narrowing scores in rheumatoid arthritis during the first 25 years of disease. Arthritis Rheum 1991;34:660-8.

8. Wolfe F. A reappraisal of $\mathrm{HAO}$ disability in rheumatoid arthritis. Arthritis Rheum 2000;43:2751-61.

9. Fuchs HA, Kaye JJ, Callahan LF, Nance EP, Pincus T. Evidence of significant radiographic damage in rheumatoid arthritis within the first two years of disease. J Rheumatol 1989;18:1585-91.

10. Van der Heijde DMFM, van Leeuwen MA, van Riel PLCM, Koster AM, van't Hof MA, van Rijswijk MH, et al. Biannual radiographic assessments of hands and feet in a three-year prospective followup of patients with early rheumatoid arthritis. Arthritis Rheum 1992;35:26-34.

11. Salaffi F, Ferracioli G, Peroni M, Carotti M, Bartoli E, Cervini C. Progression of erosion and joint space narrowing scores in rheumatoid arthritis assessed by nonlinear models. J Rheumatol 1994;21:1627-30.

12. Pincus $\mathbf{P}$, Callahan LF, Fuchs HA, Larsen A, Kaye J. Quantitative analysis of hand radiographs in rheumatoid arthritis: time course of radiologic changes, relation to joint examination measures, and comparison of different scoring methods. J Rheumatol 1995;22:1983-7.

13. Van der Heijde DMFM, van Leeuwen MA, van Riel PLCM, van de Putte LB. Radiographic progression on radiographs of hands and feet during the first 3 years of rheumatoid arthritis measured according to Sharp's method (van der Heijde modification). J Rheumatol 1995;22:1792-6.

14. Guidelines for the management of rheumatoid arthritis: 2002 update. Arthritis Rheum 2002;46:328-46. 
15. Genovese MC, Bathon JM, Martin RW, Fleischmann RM, Tesser JR, Schiff MH, et al. Etanercept versus methotrexate in patients with early rheumatoid arthritis: twoyear radiographic and clinical outcomes. Arthritis Rheum 2002;46:1443-50.

16. Breedveld FC, Weisman MH, Kavanaugh AF, Cohen SB, Pavelka K, van Vollenhoven $\mathrm{R}$, et al. The PREMIER study: a multicenter, randomized, double-blind clinical trial of combination therapy with adalimumab plus methotrexate versus methotrexate alone or adalimumab alone in patients with early, aggressive rheumatoid arthritis who had not had previous methotrexate treatment. Arthritis Rheum 2006;54:26-37.

17. St Clair EW, van der Heijde DM, Smolen JS, Maini RN, Bathon JM, Emery P, et al. Combination of infliximab and methotrexate therapy for early rheumatoid arthritis: a randomized, controlled trial. Arthritis Rheum 2004;50:3432-43.

18. van der Heijde D, Klareskog L, Landewé R, Bruyn GAW, Cantagrel A, Durez P, et al. Disease remission and sustained halting of radiographic progression with combination etanercept and methotrexate in patients with rheumatoid arthritis. Arthritis Rheum 2007; 56:3928-39.

19. Lipsky PE, van der Heijde DM, St Clair EW, Furst DE, Breedveld FC, Kalden JR, et al. Infliximab and methotrexate in the treatment of rheumatoid arthritis. Anti-Tumor Necrosis Factor Trial in Rheumatoid Arthritis with Concomitant Therapy Study Group. N Engl J Med 2000;343:1594-602.

20. Keystone EC, Kavanaugh AF, Sharp JT, Tannenbaum H, Hua Y, Teoh LS, et al. Radiographic, clinical, and functional outcomes of treatment with adalimumab (a human anti-tumor necrosis factor monoclonal antibody) in patients with active rheumatoid arthritis receiving concomitant methotrexate therapy: a randomized, placebo-controlled, 52-week trial. Arthritis Rheum 2004;50:1400-11.

21. Goekoop-Ruiterman YP, de Vries-Bouwstra JK, Allaart CF, van Zeben D, Kerstens PJ, Hazes JM, et al. Clinical and radiographic outcomes of four different treatment strategies in patients with early rheumatoid arthritis (the BeSt study): a randomized, controlled trial. Arthritis Rheum 2005;52:3381-90.

22. Aletaha D, Smolen JS. Effectiveness profiles and dose dependent retention of traditional disease modifying antirheumatic drugs for rheumatoid arthritis. An observational study. J Rheumatol 2002;29:1631-8.

23. Fox DA. Cytokine blockade as a new strategy to treat rheumatoid arthritis: inhibition of tumor necrosis factor. Arch Intern Med 2000;160:437-44.

24. Moreland LW, Schiff MH, Baumgartner SW, Tindall EA, Fleischmann RM, Bulpitt KJ, et al. Etanercept therapy in rheumatoid arthritis. A randomized, controlled trial. Ann Intern Med 1999;130:478-86.

25. van der Heijde D, Burmester G, Melo-Gomes J, Codreanu C, Martin Mola E, Pedersen $\mathrm{R}$, et al. The safety and efficacy of adding etanercept to methotrexate or methotrexate to etanercept in moderately active rheumatoid arthritis patients previously treated with monotherapy. Ann Rheum Dis 2008;67:182-8.
26. Bathon JM, Martin RW, Fleischmann RM, Tesser JR, Schiff MH, Keystone EC, et al. A comparison of etanercept and methotrexate in patients with early rheumatoid arthritis. N Engl J Med 2000;343:1586-93.

27. Weinblatt ME, Keystone EC, Furst DE, Moreland LW, Weisman MH, Birbara CA, et al. Adalimumab, a fully human anti-tumor necrosis factor alpha monoclonal antibody, for the treatment of rheumatoid arthritis in patients taking concomitant methotrexate: the ARMADA trial. Arthritis Rheum 2003;48:35-45.

28. Maini R, St Clair EW, Breedveld F, Furst D, Kalden J, Weisman M, et al. Infliximab (chimeric anti-tumour necrosis factor alpha monoclonal antibody) versus placebo in rheumatoid arthritis patients receiving concomitant methotrexate: a randomised phase III trial. ATTRACT Study Group. Lancet 1999;354:1932-9.

29. Klareskog L, van der Heijde D, de Jager JP, Gough A, Kalden J, Malaise M, et al. Therapeutic effect of the combination of etanercept and methotrexate compared with each treatment alone in patients with rheumatoid arthritis. Lancet 2004;363:675-81.

30. van der Heijde D, Klareskog L, Rodriguez-Valverde V, Codreanu C, Bolosiu H, MeloGomes J, et al. Comparison of etanercept and methotrexate, alone and combined, in the treatment of rheumatoid arthritis: two-year clinical and radiographic results from the TEMPO study, a double-blind, randomized trial. Arthritis Rheum 2006;54:1063-74.

31. van der Heijde DM, van Riel PL, Nuver-Zwart IH, Gribnau FW, vad de Putte LB. Effects of hydroxychloroquine and sulphasalazine on progression of joint damage in rheumatoid arthritis. Lancet 1989;1:1036-8.

32. Shrout PE, Fleiss JL. Intraclass correlations: uses in assessing rater reliability. Psychol Bull 1979;2:420-8.

33. Molenaar ET, Voskuyl AE, Dinant HJ, Bezemer PD, Boers M, Dijkmans BA. Progression of radiologic damage in patients with rheumatoid arthritis in clinical remission. Arthritis Rheum 2004;50:36-42.

34. Brown AK, Quinn MA, Karim Z, Conaghan PG, Peterfy CG, Hensor E, et al. Presence of significant synovitis in rheumatoid arthritis patients with disease-modifying antirheumatic drug-induced clinical remission: evidence from an imaging study may explain structural progression. Arthritis Rheum 2006;54:3761-73.

35. Landewé R, van der Heijde D, Klareskog L, van Vollenhoven R, Fatenejad S. Disconnect between inflammation and joint destruction after treatment with etanercept plus methotrexate: results from the trial of etanercept and methotrexate with radiographic and patient outcomes. Arthritis Rheum 2006;54:3119-25.

36. Bruynesteyn K, van der Heijde D, Boers M, Saudan A, Pelosi P, Paulus H, et al. Determination of the minimal clinically important difference in rheumatoid arthritis joint damage of the Sharp/van der Heijde and Larsen/Scott scoring methods by clinical experts and comparison with the smallest detectable difference. Arthritis Rheum 2002;46:913-20.

\section{BMJ Careers online re-launches}

BMJ Careers online has re-launched to give you an even better online experience. You'll still find our online services such as jobs, courses and careers advice, but now they're even easier to navigate and quicker to find.

New features include:

- Job alerts - you tell us how often you want to hear from us with either daily or weekly alerts

- Refined keyword searching making it easier to find exactly what you want

- Contextual display - when you search for articles or courses we'll automatically display job adverts relevant to your search

- Recruiter logos linked directly to their organisation homepage - find out more about the company before you apply

- RSS feeds now even easier to set up

Visit careers.bmj.com to find out more. 